\title{
Las innumerables relaciones centro y periferia
}

\section{Carlos Mallorquín*}

No quiero transmitir al lector el tiempo perdido de aquellos días en que repetía «me 〈afantasma»» (Borges, 1996:364) el libro de Víctor R. Fernández, La trilogía del erizo-zorro: redes globales, trayectorias nacionales $y$ dinámicas regionales desde la periferia; pero estoy convencido de que los comentarios, preocupaciones y críticas que siguen a continuación tienen la intención de convencer, y no desesperanzar, al lector potencial de sus importantes logros y alcance teórico. En mi defensa destaco que es el mismísimo autor quien desde sus primeras páginas remite al libro como una especie de laberinto en ciernes; a su vez un acercamiento a los contenidos del libro, a su universo, por fin me libró de la añeja incomprensión e ignorancia de los axiomas desarrollados por Borges en «La Biblioteca de Babel»: así como no existen libros idénticos, igualmente puede variar —infinitamente - la manera y el orden en que se pueden recorrer los anaqueles, me refiero a que el libro con 395 páginas, casi 50 de ellas se remiten a la guía bibliográfica que, como se sabe, por las ficciones del ilustre escribidor, aun existiendo la posibilidad de un libro «total» (Borges, 1996:469), vacía es aquella esperanza de examinarla con cierto orden predeterminado; su consulta no ofrece ese punto arquimédico, o algún anaquel que ocupe el «hexágono superior» (Borges, 1996:467) a partir del cual buscar y «consultar». A los lectores indecisos, sin intención alguna de «inquisidor» (Borges,

* Docente investigador de la Unidad Académica en Estudios del Desarrollo de la Universidad Autónoma de Zacatecas, México. Correo-e: carlosmallorquinl@gmail.com 


\section{CARLOS MALLORQUÍN}

1996:468), al respecto, sugiero que la exploración teórica arranque con dos nombres/símbolos que dispensaré más adelante.

Pero antes de mencionarlos, cabe aclarar que el libro examina la problemática teórica del «desarrollo» y cuya genealogía es producto de una guerra de interpretaciones generada en el «Sur»y, más propiamente dicho, en la región latinoamericana durante y en las postrimerías de la Segunda Guerra Mundial.

Sustancialmente el libro es un examen teórico de lo que el autor llama «nor-teorías»; se presenta una justificada y pormenorizada disquisición persecutoria de las categorías sociales que dominan y que pasan por «ciencia social» en el universo conceptual anglosajón o eurocéntrico. La longitud del título es obligatorio debido a la extensión del periodo y espacio al que se remite: La trilogía del erizo-zorro: redes globales, trayectorias nacionales y dinámicas regionales desde la periferia.

Se propone explorar la evolución, los entramados de la «economía global», el «Norte global y el Sur global», y sus respectivos «centros de respuesta», ante las asimetrías de poder desde su fase capitalista «competitiva», que transita hacia la época global actual, mediante la superación/ incorporación de la etapa previa «monopolista». El lugar ocupado por el «Sur global», como su propia imagen geográfica lo señala, a pesar de la heterogeneidad supuesta, incorpora a América Latina y a los países del sudeste de Asia, los llamados «tigres», y China. Sin duda la exposición exige muchas páginas, en términos que el autor destaca como «holísticos», explorar lo que se supone una «totalidad» mundial, bajo la égida de algún mecanismo general y sus condiciones de existencia.

Si el término «metodología» viene al caso, como una lógica de investigación/presentación, la fábula del «erizo-zorro» funge como tal: se subraya 
la intención de ofrecer un análisis detallado de lo particular y simultáneamente lograr subsumirlo teóricamente a partir de unas proposiciones más generales.

Los capítulos dos, ${ }^{2}$ tres $^{3}$ y cuatro ${ }^{4}$ del libro respectivamente, presentan la discusión de tres distintas problemáticas teóricas y prácticas, o «enfoques», "generados en el Norte» e instalados en el Sur para pensar las lógicas productivas y su articulación entre dichos «espacios». Es por medio de la «Introducción» (23-48) y el primer capítulo (49-84) ${ }^{5}$ que el autor destaca la «totalidad» y su evolución económica; las distinciones en el ritmo de «crecimiento», productos, comercio e inversión extranjera, así como las trayectorias diversas dentro y entre las mismas regiones ya sea Norte y Sur globales. ${ }^{6}$ Ocupa igualmente un importante lugar la idea de examinar «escalarmente» las regiones Norte y Sur e intra-regionalmente ciertos espacios para comprender las desigualdades sociales y espaciales entre sí, así como los procesos evolutivos que generan procesos «desiguales» de concentración de ingreso y asimetrías de poder.

El segundo capítulo cuestiona, problematiza, la noción actual de «cadena de valor global» (CVG), la cual habiendo superado y transformado la noción pretérita como aquella que sencillamente examinaba una «red de procesos laborales y productivos, (los commodity chains) o cadenas de

${ }^{2}$ «Transformaciones globales: hacia una revisión crítica del enfoque de cadenas de valor desde el Sur global» (Hernández, 2017:85-131).

${ }^{3}$ «Trayectorias nacionales en la globalización: revisión y alternativas a las variedades de capitalismo» (Hernández, 2017:133-218).

${ }^{4}$ «Dinámicas regionales en variedades capitalistas periféricas. Desde la crítica a las alternativas al nuevo regionalismo» (Hernández, 2017:219-333)

${ }^{5}$ «Jerarquías globales y emergencia del Sur global: trayectorias diferenciadas».

${ }^{6}$ Los datos suministrados por el autor sobre la evolución de dichas entidades, «Norte» y «Sur», pueden complementarse con los que presenta (Ocampo, 2015; Titelman y Pérez, 2015). 


\section{CARLOS MALLORQUÍN}

mercancías, se ha reteorizado en una concepción que supone reconsiderar las estrategias y la generación de capacidades de las unidades productivas en el Sur global para incorporarse, integrarse, a las «redes económicas globales», cuyas matrices productivas claves se encuentran en el Norte y cuya discusión sigue en proceso ${ }^{7}$ (capítulo cuya discusión pormenorizada implicaría otro libro). La limitante conceptual principal del CVG es la ausencia de una teoría del poder que explique las lógicas productivas entre el Sur y el Norte, consecuencia teórica de haberse distanciado de la Teoría del Sistema Mundo (TSM). Para describir la evolución contrastante y «desigualante» social y espacial entre el Norte global y el Sur global, y comprender las variedades de capitalismos se recupera de la TSM, cuya estructura elemental remite a las tres contradicciones.

En otras palabras, las empresas del o en el Sur que han logrado articularse a las cadenas globales de valor lo hacen ocupando tareas productivas cuyo valor agregado es menor, así como el contenido tecnológico, pues las empresas transnacionales han domiciliado previamente a la «matriz», en el Norte, aquellas fracciones tecnológicas primordiales.

La TSM supone tres contradicciones clave, relación capital-trabajo («contradicción fundacional», explotación), capital-capital (competencia) y la apropiación privada de excedentes y con el imperativo de «socializar» las condiciones para reproducir el capital y la mano de obra. Por medio de la «triple y articulada dinámica contradictoria y su multiplicidad de cambios es que encuentran comprensión las «tres grandes variaciones de capitalismo»» (Fernández, 2017:159). Se trata de una «totalidad» (centros-periferias) autoconstituida, cuya dinámica «holística» genera las variaciones

${ }^{7}$ Véase, por ejemplo, Marichal, Topik y Frank (2017). 
entre «capitalismos», consecuencia de las distintas formas en que se resuelven o no («variación de respuestas») (Fernández, 2017:159) las contradicciones intranacionales, o entre naciones, centros y periferias, Norte y Sur.

Con la incorporación de la TSM, se intenta explicar la dinámica de la acumulación en y del Sur y sus consecuencias, sociales y espaciales internas, con la superación del «nacionalismo metodológico», dominante en el enfoque CVG. Esa discusión teórica explica la aparición de ciertos instrumentos teóricos para examinar los antagonismos comerciales y sus mecanismos de «penetración» económica, tanto financiera como productiva: Redes Económicas Globales (REG) y Redes Políticas Globales (RPG). Dichos dispositivos conceptuales son el sustento para reflexionar sobre la cooptación de organizaciones e instituciones oficiales por parte de las instituciones financieras mundiales y sus visiones en torno a la inversión, acumulación y reglas «permisivas» para distintas regiones durante variados periodos históricos.

Así como en el segundo capítulo, en el tercero se realiza primero una descripción y discusión genealógica conceptual del enfoque a discutir: las «variedades de capitalismo» (VC). Los modelos de gobernanza del modelo de capitalismo norteamericano y el europeo generan Sistemas Sociales de Producción (SSP) diversos entre sí, los cuales explicarían los diversos performances económicos en el nivel nacional. Se intenta, bajo el lema de las «variedades del capitalismo», analizar específicas variedades nacionales de capitalismo, lo cual impone examinar aspectos institucionales de las formas que amparan tanto la intervención estatal y formas de acumulación, así como la participación laboral en el proceso. Aquí se plantea que existen condiciones institucionales que están articuladas a las REG y RPG, dominadas por las empresas transnacionales. 


\section{CARLOS MALLORQUÍN}

Históricamente, la evolución, crisis y transformación de los centros y las periferias se presentan en un contexto capitalista, cuyas fases «competitivo», «monopólico» y «global», explicarían las vicisitudes y las respectivas performances de aquellas regiones cuyas capacidades de «respuesta» $\mathrm{O}$ sistema «inmunológico» en algunos casos fue «positivo, logrando «salir» de la periferia como aparentemente serían los afamados «tigres` en el Sudeste de Asia» más recientemente y Japón en una fase previa. El dispositivo teórico señalado se transfiere sistemáticamente para observar las relaciones y las jerarquías entre regiones, geografías, centro y periferia, Norte y Sur (América Latina y Sudeste de Asia). Dicho proceso de jerarquización y dominio regional es presentado bajo el lema de la existencia de un «bloque histórico transnacional» (Fernández, 2017:180), lo cual obliga a recapacitar la noción de los actores supuestos en las RPG, no tanto como una serie de instituciones políticas, hegemonizadas por cierto aparato discursivo/ conceptual «neoliberal», sino una «clase transnacional» cuyas condiciones de existencia deben presuponerse. La distinción entre «fronteras», Estados, y las diversas formas de posesión en separación de las condiciones de producción, difícilmente armoniza con una idea de una noción de «clase» como «categoría económica». Otra forma de decir lo mismo es señalar que las formas culturales de comportamiento o discurso conceptual entre diversos agentes en y entre regiones dificultan, si es que no ocultan, esas condiciones que hacen posible hablar de «clase» como entidad que posee (en separación) algunas de las condiciones de producción.

Vale la pena en este contexto, no obstante la «naturaleza informe y caótica de casi todos los libros» (Borges, 1996:466), sincerarme con mi ilusorio capricho e inútil deseo de convertirme en «jefe de un hexágono superior» (Borges, 1996:467), indicando a uno de los dos autores/símbolos del anaquel 
de la biblioteca «ilimitada» (Borges, 1996:471), que «afantasma» el discurrir del libro de Fernández:

Como expresa Jessop: «Las estructuras son, de esta manera, tratadas analíticamente como estratégicas en su forma, contenido y funcionamiento, y las acciones, de ese modo, se tratan analíticamente como estructuradas, más o menos sensible al contexto, y estructurantes. La aplicación de este enfoque implica el examen de cómo una estructura dada puede privilegiar algunos actores, algunas identidades, algunas estrategias, algunos horizontes espaciales y temporales, algunas acciones sobre otras; y las formas, en su caso, en el que los actores (individuales y/o colectivos) tienen en cuenta ese diferencial privilegio a través del análisis «contextual-estratégico» cuando eligen un curso de acción» (Jessop, 2001:1223, citado en Fernández, 2017:175).

El autor del libro comentado tendrá algún día, sin caer en la «depresión total» (Borges dixit), que definir la distancia y por tanto importancia, entre los anaqueles hexagonales que comprenden los «símbolos», «Jessop» $\mathrm{y}$ «Wallerstein» para pensar «el centro y la periferia».

Con la construcción de la noción de una REG, liderada por las empresas transnacionales, aparece el sustento para reflexionar sobre el «espacio transnacional» (Fernández, 2017:178), articulado a través de una RPG, entre Norte y Sur, que genera las jerarquías espaciales y económicas. Lo anterior supone a su vez examinar los mecanismos institucionales, los aparatos (como dirían los althusserianos) mediante los cuales se imprime una lógica productiva, una forma específica y divergente de acumulación para realizar el proceso («impostergable») de industrialización («competitiva»), en y entre el centro y la periferia, Norte y Sur. 


\section{CARLOS MALLORQUÍN}

Para ello se recupera el segundo «símbolo» autoral prometido de la biblioteca imposible: Fernando Fajnzylber (1983), cuyo término «núcleo de acumulación» (NA), ${ }^{8}$ apoyado en o producto del «núcleo de implicación estatal» (NIE), ${ }^{9}$ generado por Fernández, obliga a pensar la organización y la articulación de la división técnica y productiva del proceso de acumulación.

Anteriormente mencioné: «apoyado en o producto del» debido a que no se sabe con certeza si los supuestos aspectos productivos virtuosos de generar internamente (lo endógeno) o asociarse (para el Sur), a empresas de capacidad y cualidad tecnológica de punta, es consecuencia o punto de partida en términos del NA; «viceversa» dice Fernández (2017:189), ya que el NIE impone recapacitar las formas y alianzas políticas e institucionales para generar las «respuestas» o defensas «inmunológicas» pertinentes en el Sur. El Sur global, en particular América Latina, presenta «respuestas» más en el sentido de «acoplamiento» a la evolución capital-financiero de la época «global»; sin alterar, en contraste con algunas regiones del Sudeste de Asia, su condición «periférica» en términos de inserción comercial internacional.

En contraposición a algunos países del Sudeste de Asia, los denominados «tigres», el NA en América Latina, el «NIE desde su interacción con el NA», no «atravesaron un círculo virtuoso de inserción externa e inversiones

8 «Estructura de control del capital: endógeno-exógeno, concentrado-desconcentrado (...) aprendizaje-innovación (...) fracciones del capital financiero con el capital productivo (...) forma de inserción internacional de los procesos de producción (vías altas de mayor valorización o vías bajas de los recursos naturales)» (Fernández, 2017:189).

${ }^{9}$ «Estructuras estatales (organización meritocrática o patrimonial), forma conceptual-operativa del staff (...) tipo de control y direccionamiento estatal del financiamiento» (Fernández, 2017:189). 
internas» (Fernández, 2017:198), ni fueron favorecidos por retornos crecientes del capital o productividad; y en lo que respecta al NIE, sus acciones tampoco fueron exitosas: «sus estrategias interventivas (combinadamente disciplinantes y coproductivas) no 〈ganaron〉 legitimidad» (Fernández, 2017:198). Los sectores y actores cuyo historial productivo («protegido», «rentista») delimitaba sus horizontes a corto y largo plazos, consecuencia de la evolución de lo que fue llamado el proceso de industrialización sustitutiva (ISI) fracasado, obstruyeron un centro de «respuestas» estratégicas adecuadas ante la nueva configuración histórica del capitalismo global bajo la hegemonía de las reglas del Consenso de Washington, explícita en las instituciones internacionales que dominaban las redes económicas y políticas globales (REyPG).

No se olvida tampoco del ámbito geopolítico muy distinto para América Latina, en contraste con el que reina en el Sudeste de Asia («permisivo»); de las estrategias que apoyaron la evolución y expansión territorial-geográfica del proceso endógeno de la industrialización geográfica, bajo el modelo del «ganso volador» (flying geese).

Con la intención de demostrar que el «capitalismo» engendra variedades surge la posibilidad de utilizar las nociones del NA y NIE, en diferentes regiones-espacios, especialmente en el Sur global:

Las particularidades e interrelaciones en ambos núcleos (NA y NIE), precisando tanto sus necesarias propiedades, como la presencia y desarrollo de estas últimas bajo las especificidades de un determinado proceso histórico, en el que se combinan las permisividades (Sudeste de Asia) u obstaculizaciones (América Latina) externas y las viabilidades (Sudeste de Asia) o inviabilidades (América Latina) internas. (...) las instancias que operaron cohesionadamente 


\section{CARLOS MALLORQUÍN}

como centros de respuesta ante las REyPG, fueron desarrolladas en el Sudeste de Asia a partir de la posguerra, esencialmente con base en la capacidad de conformar NA dominados por la endogeneidad y dinamismo en el proceso de generación del excedente. Ello viabilizó un patrón productivo y social más cohesivo y, conjuntamente, una inserción externa que alteró las formas subalternas de ingresar desde la periferia a las REG, cuestionando la inviabilidad determinista contenida en buena parte del dependentismo (...) el dispositivo conceptual en torno a los núcleos (NA y NIE) y sus vínculos constituyen no sólo un herramental para el análisis histórico de las diferenciadas trayectorias del capitalismo al interior del Sur global, sino que también contiene la capacidad de introducir — dentro del análisis de variedades — la consideración de las pautas o elementos que viabilizan dentro de determinadas trayectorias nacionales el desarrollo de un «cambio mayor» conducente, bajo la lógica contradictoria de reproducción del capitalismo, a una salida al posicionamiento periférico (...) contribuye a esclarecer cuáles son las condiciones de acumulación e implicación estatal —al menos nacionales_ que deben reunirse en los territorial fix de la periferia para compatibilizar patrones de cohesión interna e inserción/coproducción dinámica en las contradictorias y conflictuales formas de reproducción de las REyPG, aspectos ausentados tanto en el enfoque de CVG (...) como en el de VC» (Fernández, 2017:211-212).

Habiendo postulado una serie de categorías para pensar las particularidades o especificidades del capitalismo, a partir de la incorporación «holística» de las tres contradicciones del TSM, los NA y NIE, y sus relaciones con las REyPG, el capítulo cuarto intentará deconstruir la categoría de lo «regional» por improcedente e incapaz para comprender la evolución de las desigualdades sociales y espaciales, que eran precisamente su «objeto» 
teórico por excelencia. El «nuevo regionalismo» en América Latina se propuso diagnósticos y estrategias para superar las «desigualdades espaciales» y la exitosa campaña de las REyPG para difundir aparentemente los modelos fundamentados en los modelos en el Sudeste de Asia, por medio del traslado de diversas etapas productivas industriales a lo largo de cierto espacio geográfico entre diferentes naciones, los llamados modelos de vuelo del ganso (flying geese), en remedo a su migración cíclica.

Se describen algunos aspectos de la evolución transitada del capitalismo desde su fase competitiva, monopólica, a su actual configuración global, con el afán de incorporar aspectos «multiescalares» y jerarquías para representar especificidades de las políticas de inversión, y sus performances en unir, articular, «integrar», distintas regiones desiguales entre sí. Forma parte de ello una «regulación multiescalar» que intenta superar los antagonismos entre el capital global y el local. La multilocalización de diversos aspectos productivos de las unidades productivas o empresas transnacionales, dispersas mundialmente, supone más bien una viable y firme intervención estatal, no su desaparición. Es en el centro donde caben intervenciones de estilo soft (Fernández, 2017:242), no en la periferia. Es ahí donde las RPG ocupan un lugar de primer orden, para reglamentar y construir reglas a través de las instituciones supranacionales entre Estados y organizaciones internacionales financieras (Banco Mundial, Fondo Monetario, Banco Interamericano de Desarrollo). Así, en la periferia se difunden toda una serie de estrategias y «financiamiento» para desregular, desmantelar los acuerdos, leyes e instituciones generados en América Latina durante su industrialización sustitutiva de posguerra.

Se reconstruyen nuevos «territorios fixes», entre actores y territorios, incorporando transnacionales que controlan las REG, a la vez que se amortiguan 


\section{CARLOS MALLORQUÍN}

algunos aspectos sociales y espaciales negativos del desmantelamiento acumulativo en proceso por el aperturismo comercial. Lo «macroregional particularizado», debido a la heterogeneidad de sus formas productivas, su multiplicidad implica tanto un proceso de upscaling o downscaling estratégico, en los niveles nacional y regional, como alternativas para contrarrestar las políticas de desmantelación productiva. Ahora

ya no se trata sólo de una lógica de «acumulación por desposesión», sino también de una «acumulación por subsidio» fundada en un «inclusivismo fragmentario», impulsado a partir de una arquitectura institucional que «selecciona» las «ayudas» y coloca a los actores incluidos en el soporte de un registro discursivo que disuelve las formas de reproducción contradictorias y subalternizadoras que resultan de la intersección de las lógicas de flujos — que empoderan a los multilocalizables actores transnacionales de las REG - con lógicas territoriales - donde habitan los actores locales potencial o efectivamente seleccionados para integrar los encadenamientos globales (Fernández, 2017:247).

Es en el espacio dedicado a las políticas «regionales» donde mejor se comprende la crítica de Fernández, a la desprolija, sino que subalterna, participación de los intelectuales y consultores en los proyectos de integrar lo global a lo local. Lo que está en juego son las reconstrucciones de las zonas centrales periféricas dentro de las diversas lógicas productivas, ya sea por medio de la intensificación tecnológica de la división técnica del trabajo, o sencillamente ampliar la subsunción de mayores espacios para extraer productos o recursos naturales. A su vez, en algunos Estados en la periferia se presentan actores, transnacionales o no, cuyas capacidades de actuar productivamente al estilo schumpteriano y con empresas transnacionales 
presuponen necesariamente cierto tipo de alianzas dentro del marco de las REG.

En la periferia, entonces, las nociones de los NA y NIE son de primera importancia para observar las políticas de inserción que realicen o supongan virtuosas las relaciones entre lo local y lo global, el territorio fix. El autor insiste, al contrario de lo sucedido en el Sudeste de Asia, que en América Latina los actores fueron «cooptados y direccionados por los grupos capitalistas más concentrados» (268). Por otra parte, de ello se deriva que la «Configuración socioproductiva, institucional y espacial» (CSPIE) haya generado un proceso de diversa y contrastante desigual evolución en y entre regiones del Sur global (Sudeste de Asia y América Latina), tanto en términos sociales como espaciales. Como ya se mencionó, en el Sur global, en la zona del Sudeste de Asia, el NA y el NIE tuvieron una transición virtuosa social y económicamente, apoyada por la permisividad de Estados Unidos y sus regiones adyacentes. Incluso se habla de que en la fase globalizadora del capitalismo, Japón y países de ingreso medio (Corea-Taiwán), lograron «salir del posicionamiento periférico» (Fernández, 2017:286). No obstante el crecimiento y una relativa «igualdad social» de la zona del Sudeste de Asia, las desigualdades espaciales (urbanas-rurales, provincias-Estados) no observan esa tendencia, más bien se observa cierta concentración espacial de las actividades y flujos productivos:

América Latina, sin embargo, ha transitado al interior de la periferia un $c a-$ mino inverso al del Sudeste de Asia, como resultado de las formas diferenciadas en que se fueron constituyendo, (...) los NA y los NIE y las relaciones de éstos con las REyPG. Mientras que en el Sudeste de Asia la presencia —más reciente- del NR y la producción de dinámicas regionales actuaron como 


\section{CARLOS MALLORQUÍN}

una herramienta funcional al neoliberalismo para debilitar/desmantelar las formas endógenas y los NIE con capacidad de direccionamiento de los NA hacia esas formas, en América Latina debe observarse el modo en que el NR y las dinámicas regionales se han plegado y funcionalizado activamente desde un inicio dentro de una compleja intersección multiescalar para impedir la conformación de un NIE que viabilice la configuración endógena de los NA (Fernández, 2017:298).

La configuración de la política social, el autoritarismo burocrático latinoamericano, el «desempate catastrófico» (Fernández, 2017:301) entre las fuerzas políticas, o sea la ausencia de una hegemonía, del régimen, inhabilitan la generación de un NA o NIE virtuoso. El NIE buscó una «ingeniería de intervención», ya sea bajo una suerte de «autoritarismo de baja o alta intensidad» que explica la lógica productiva «costo placista» de la región, abandonando proyectos de inversión y proyectos sociales «inclusivistas». Un «aperturismo» comercial con muy pocas alternativas para selectivamente construir los NA que suponen el universo heterogéneo de la región latinoamericana, acompañado de un NIE que puede definirse como «operativamente «deformante». En otras palabras, la deficiente arquitectura institucional se muestra en la «carencia de capacidad competencial y organizacional» (Fernández, 2017: 322) para condicionar a los actores que «dinamizan ese NA» (Fernández, 2017: 322), cuya participación intentó seguir algunas de las políticas institucionales locales en torno, por ejemplo, de las cadenas globales de valor, o sea, políticas de acoplamiento al instrumental del nuevo desarrollismo regional.

El relato elaborado hasta aquí, cuyo orden cronológico obedeció a la organización del texto de Fernández, confiesa que eludió desde un comienzo 
manifestar que lo escrito hasta este punto sería superfluo en calidad y forma, si hubiera dicho al lector que mejor leyera las «Conclusiones generales», donde aparecen una introducción formidable y una síntesis del libro.

Por lo tanto, y para finalizar, si ahora se me permiten algunas palabras, quiero insistir en que la referencia al final del libro por parte de Fernández, en torno al aspecto «transgresor» (Fernández, 2017:344) del pensamiento latinoamericano, implica enfrentar y rendir cuentas ante un «inquisidor» (Borges dixit) y del «hexágono superior» (Fernández, 2017:344), donde, como fue mi caso, llegué rendido. Igualmente, el símbolo «Jessop» observa un anaquel que presenta una bifurcación inagotable alejándose interminablemente de «Wallerstein» y habiendo transitado varias escaleras e incontables hexágonos, el anaquel en el que figuraba «Fajnzylber» conducía, de manera extenuante, hacia otro que leía «Prebisch» y leguas distantes de hexágonos, más tarde «Furtado» y otros más en los cuales a distancia percibí algo como «cepalinos», cuyos nombres ya no recuerdo... pero que sin duda alguna vale la pena recuperar.

\section{Referencias}

Bárcena, Alicia y Antonio Prado (eds.) (2015), Neoestructuralismo y corrientes heterodoxas en América Latina y el Caribe a inicios del siglo XXI, Santiago de Chile, Comisión Económica para América Latina y el Caribe.

Borges, Jorge Luis (1996), Ficciones, Buenos Aires, Emecé Editores. (1996), Historia de la eternidad, Buenos Aires, Emecé Editores.

Fajnzylber, Fernando (1983), La industrialización trunca de América Latina, México, Nueva Imagen. 


\section{CARLOS MALLORQUÍN}

Jessop, Bob (2001), «Institutional re(turns) and the strategic-relational approach», Environment and Planning, $A, 33(7)$.

Marichal, Carlos, Steven Topik y Zephyr Frank (coords.) (2017), De la plata a la cocaína, México, Fondo de Cultura Económica.

Ocampo, José Antonio (2015), «América Latina frente a la turbulencia económica mundial», en Alicia Bárcena y Antonio Prado (eds.), Neoestructuralismo y corrientes heterodoxas en América Latina y el Caribe a inicios del siglo XXI, Santiago de Chile, Comisión Económica para América Latina y el Caribe, pp. 93-110.

Ramiro Fernández, Víctor (2017), La trilogía del erizo-zorro: redes globales, trayectorias nacionales y dinámicas regionales desde la periferia, España/Argentina, Anthropos/Universidad Nacional del Litoral.

Titelman, Daniel y Esteban Pérez Caldentey (2015), «Macroeconomía para el desarrollo en América Latina y el Caribe: nuevas consideraciones sobre las políticas anticíclicas», en Alicia Bárcena y Antonio Prado (eds.), Neoestructuralismo y corrientes heterodoxas en América Latina y el Caribe a inicios del siglo XXI, Santiago de Chile, Comisión Económica para América Latina y el Caribe, pp. 155-184. 